\title{
Reactions to contemporary narratives about masculinity: A pilot study
}

\author{
John Barry, Rob Walker, Louise Liddon, \&t Martin Seager
}

Male Psychology Network

United Kingdom

Correspondence: john@malepsychology.org.uk

Masculinity is frequently talked about in contemporary Western media as being in crisis, needing reform or even being 'toxic'. However, no research to date has assessed the impact that this pervasive narrative might be having on people, particularly men themselves. This cross-sectional online pilot survey asked 203 men and 52 women (mean \pm SD age $46 \pm 13$ ) their opinions about the terms toxic masculinity, traditional masculinity, and positive masculinity, and how they would feel if their gender was seen as the cause of their relationship or job problems. Most participants thought the term toxic masculinity insulting, probably harmful to boys, and unlikely to help men's behaviour. Having feminist views, especially being anti-patriarchy, were correlated with more tolerance of the term toxic masculinity. Most participants said they would be unhappy if their masculinity or femininity were blamed for their work or relationship problems. Further analysis using multiple linear regression found that men's self-esteem was significantly predicted by older age, more education, and a greater acceptance of traditional masculinity. Men's mental positivity - which is known to be negatively correlated with suicidality - was significantly predicted by older age, a greater acceptance of traditional masculinity, and more education. Implications for the mental health of men and boys are discussed in relation to the narrative around masculinity in the media, social sciences, and in clinical psychology.

Keywords: feminism; gamma bias; patriarchy; self-esteem; toxic masculinity 
Until around the 1980s, masculinity was typically described using adjectives such as 'active', 'dominant', 'self-contained' (e.g., Cicone \& Ruble, 1978) and 'aggressive' (Spence et al, 1975). However, recently masculinity has increasingly been constructed using attributes such as 'misogyny' and 'homophobia' (Mahalik et al., 2003). This represents a blurring of normative traits that are common to most men, with deviant traits which are manifest in a minority (Ferguson, 2018). These more recent conceptions originated in sociology, mostly in relation to 'hegemonic masculinity' (Connell, 1987), which claims masculinity is about striving for dominance, including dominance over women. Similarly, in 'critical psychology' - inspired by Marxist ideas - men are sometimes portrayed as a dominant class who oppress women as a class, and 'male privilege' and 'patriarchy' are constructed as problems in relation to masculinity (Arfken, 2017; Nicolson, 2010).

Toxic masculinity is described as 'the constellation of socially regressive male traits that serve to foster domination, the devaluation of women, homophobia, and wanton violence' (Kupers 2005, p.710), and has become synonymous with violence and sexual assault by men. In 2018 'toxic' was voted Word of the $Y e a r$, and - in a year of great concern over environmental pollution - the phrase 'toxic masculinity' was ranked second only to 'toxic chemicals'. The Word of the Year is chosen by the Oxford University Press to reflect the preoccupations of society that are most likely to have lasting cultural significance, and the widespread use of the term 'toxic masculinity' probably reflects the culmination of several decades of negativity about men and masculinity. This raises the possibility that the term now shapes how men are perceived, foregrounding toxicity over and above the law-abiding and positive behaviours of most men (Barry, 2017).

There is evidence that feeling good about masculinity boosts men's self-esteem (Burkley et al., 2015) and some research shows that low self-esteem is correlated with suicidal ideation (De Man \& Gutiérrez, 2002). There is research suggesting that boys are more quickly associated with negative attributes than are girls (Heyman, 2001). Giving someone a 'bad name' can lead to bad behaviour (Sharma \& Sharma, 2015), and it is suggested that without being given a way to develop a healthy identity, many boys are likely to opt for an unhealthy identity (Nathanson \& Young, 2009; Acharya \& Relojo, 2017). However, so far, no research on the influence on men and boys of negative language about masculinity has been conducted.

The aim of the present study was to pilot questions about how people feel about various conceptions of masculinity, and whether such views are related to self-esteem.

\section{METHOD}

Design

This study is a cross-sectional online survey analysed using multiple linear regression. The dependent (criterion) variables were self-esteem and mental positivity. The predictors were (a) age; (b) education level; (c) attitudes to masculinity (i.e., attitudes to traditional, toxic, and positive masculinity); and, (d) and feminist attitudes (i.e., identifying as feminist, equal opportunities, and anti-patriarchy). Data were analysed using SPSS software, Version 26. The survey platform was PsyToolkit.

Materials

Types of masculinity. All participants were presented with the statement: In general, masculinity can be defined as the set of characteristics, behaviours and social roles usually associated with men. The following questions ask your opinion on different types of masculinity.

This was followed by three descriptions of masculinity. Participants saw all three descriptions, but the order of presentation was randomised: 
Description 1: The term 'traditional masculinity' is sometimes used to describe traditional male behaviours, such as being a provider and protector of the family, someone who is prepared to fight for the things he values in life, and someone who keeps their problems to themselves. Please answer the following questions about your opinion of traditional masculinity, stating the extent to which you agree with the statements.

Description 2: The term 'toxic masculinity' is sometimes used to describe men's behaviour that is socially dominant, misogynistic, violent or homophobic. Please answer the following questions about your opinion of toxic masculinity, stating the extent to which you agree with the statements.

Description 3: The term 'positive masculinity' is sometimes used to describe men's behaviour that is socially useful. For example, some men like to take dangerous risks, and becoming a firefighter is a positive way to channel risk-taking behaviour. Please answer the following questions about your opinion of positive masculinity, stating the extent to which you agree with the statements.

After each of these descriptions, the following questions were asked, with the name of the type of masculinity varied as appropriate. The question also varied depending on whether the participant was male, female, or other gender:

The idea of 'toxic masculinity' helps me to behave in a good way. [Asked to male participants only]

The idea of 'toxic masculinity' helps men in general to behave in a good way.

The idea of 'toxic masculinity' might make my [or men's] behaviour worse.

The idea of 'toxic masculinity' is insulting to me [or men].

The idea of 'toxic masculinity' changes the way all men are seen, not just the 'toxic' men.

The idea of 'toxic masculinity' may have a harmful impact on boys if they hear or read about the term.

The idea of 'toxic masculinity' is helpful.

The response options were on a 6-point Likert scale from 'very much agree' to 'very much disagree'.

Two other questions were asked, with changes appropriate to the gender of the participant:

Question 1: If you were feeling down about problems in your relationship due to having arguments, and you were told that your problems were caused by your masculinity lor femininity, or gender], how would you feel?

Question 2: If you were feeling down because your job was making you stressed and you were told that your problems were caused by your masculinity [or femininity, or gender], how would you feel?

The response options were the Positive Mindset Index (PMI; Barry et al., 2014) items (happy, confident, in control, emotionally stable, motivated and optimistic).

Feminist attitudes. There were three items: (a) I am a feminist, (b) Women should have equal opportunities to men; and (c) Patriarchy prevents women from having equal rights to men. The response options were on a 6-point Likert scale from 'very much agree' to 'very much disagree'.

Positive Mindset Index. The PMI consists of six items (happiness, confidence, being in control, emotional stability, motivation, and optimism), and uses a 5-point Likert scale. This scale shows good internal reliability (Cronbach's alpha $=0.926$ ) and good concurrent validity with the psychological subscale of the SF-12 $(r=.678)$. There is also good concurrent validity between the PMI and Paykel's 
(1974) Suicidal Ladder ( $r=-$.539) (Seager et al., 2014). Phillips et al., (2018) found good concurrent validity with PsyCap (a measure of an appealing personality; $r=.687$ ) and the Subjective Happiness Scale $(r=.689)$. The norm score for the PMI is around $3.3(0.8)$ for men and women combined.

Self-esteem. Self-esteem was measured using Rosenberg's (1965) scale, a 10-item measure of global selfworth. Positive and negative feelings about the self are assessed on a single dimension. Cronbach's alpha for various samples range from 0.77 to 0.88 (Blascovich \& Tomaka, 1993). Scores between 15-25 indicate normal self-esteem. Items are answered on a 4-point Likert scale, from 'strongly agree' to 'strongly disagree'. The present study used a 6-point scale, and scores were converted to be comparable to the scores and norms on the original scale using the algorithm: score minus 1 , then: $5=3.33 ; 4=2.67 ; 3$ $=2 ; 2=1.33 ; 1=0.67 ; 0=0$.

Free text responses. Free text responses were reviewed and coded using content analysis (Graneheim \& Lundman, 2004). The free text was reviewed by RW and recurring themes tallied and given an appropriate label.

\section{Participants}

Participants were recruited via social media, with the initial post on the Male Psychology Network Twitter account being subsequently shared more widely. Participants were excluded if they were under 18 years old, did not complete the consent form, or did not give key information (e.g. age, gender or attitudes to masculinity). Participants indicated their informed consent to take part by ticking a box which followed an information sheet. The survey was anonymous and confidential, and done in accordance with the ethical guidelines of the Declaration of Helsinki (World Medical Association, 2013).

Procedure

Participants answered an invitation on social media, posted initially on the Male Psychology Network social media channels. After reading an information sheet and indicating their consent with a tick box (compulsory for participation), participants filled in the questionnaire. Three types of masculinity were described, with the order of their presentation being randomised. The survey took around 15 minutes to complete.

\section{Statistical analyses}

Demographic data were analysed using independent t-tests or $\chi^{2}$. Opinions about masculinity were presented as percentages. Pearson's correlations were used to assess relationships between variables. All statistical analyses had a sufficiently large sample size ( $>50$ ) to use parametric tests regardless of the shape of the distribution (Hinkle et al., 2003), based on the central limit theorem (Pek et al., 2018). According to Tabachnick and Fidell (2001), for multiple linear regression, the minimum number of participants should be $>50+\left(m^{\star} 8\right)$, where $m=$ the number of predictors. In the present study, with 8 predictors this means the minimum number required was 114 . To detect a moderate effect size with $80 \%$ statistical power, a minimum of 52 participants are needed per group for independent t-tests, and at least 100 participants are needed for Pearson's correlations (Cohen, 1988).

\section{RESULTS}

Two hundred and seventy-nine people responded to the survey. Twenty-four people (8.6\%) didn't answer one or more key question, so were omitted from the study. Most participants were born in the British Isles (57\%), 13\% were from other parts of Europe, 18\% were from the US or Canada, $7 \%$ from Australia or New Zealand, and 5\% from other countries. Table 1 shows the descriptive statistics and comparison by gender for background characteristics of the participants. 
Table 1

Comparisons by Gender for Background Characteristics.

\begin{tabular}{llll}
\hline & Men $\left(N=203^{\mathrm{a}}\right)$ & Women $\left(N=52^{\mathrm{b}}\right)$ & Test statistic \\
\hline Age: Mean (SD) & $44.86(12.94)$ & $46.68(13.19)$ & -.093 \\
Ethnicity (White) & $191(90.5 \%)$ & $50(94.7 \%)$ & 17.787 \\
Undegraduate degree or higher & $133(68.7 \%)$ & $43(76.8 \%)$ & 7.097 \\
Employed full-time & $131(62.1 \%)$ & $18(32.1 \%)$ & $28.71^{* * * *}$ \\
Relationship: Married & $72(34.1 \%)$ & $24(42.9 \%)$ & 2.52 \\
Relationship: (Single) & $87(41.2 \%)$ & $22(29.3 \%)$ & \\
Heterosexual & $186(88.2 \%)$ & $51(98.2 \% 0$ & 5.369 \\
Politics: Conservative & $61(28.9 \%)$ & $14(25.0 \%)$ & \\
Politics: Labour/Liberal & $54(29.3 \%)$ & $13(29.4 \%)$ & 3.168 \\
Democrats/Green/Other Party & $86(40.8 \%)$ & $25(44.6 \%)$ & \\
Politics: No party & & & \\
\hline
\end{tabular}

NB: Values are shown as mean (SS) or frequency count (with percentage).

${ }^{*} p<.05 ;{ }^{* *} p<.01 ;{ }^{* * *} p<.001$ (two-tailed)

${ }^{a}$ Numbers vary where participants did not give full demographic information.

${ }^{b}$ All test statistics are $\chi^{2}$, apart from Age which is mean (SD)

The PMI and self-esteem scores were within the normal range for these scales. PMI and self-esteem were strongly correlated $\left(r=.766 ; \mathrm{n}=273 ; \mathrm{p}<0.05^{-51}\right)$, indicating good concurrent validity. Not shown in Table 2, 22.8\% of the men and 53.6\% of women agreed to some degree ('very much', 'moderately', or 'slightly') that they were a feminist. $96.3 \%$ of men and $100 \%$ of women agreed to some degree with equal opportunities for men and women. $15.6 \%$ of men and $42.9 \%$ of women agreed to some degree that patriarchy prevents women from having equal rights to men. For all the participants combined, scores on the feminism item and patriarchy item were strongly correlated $\left(r=.589 ; p<.05^{-24}\right)$, scores on the feminism item and equal opportunities item were significantly correlated though more weakly $(r=.172$; $p<.005)$, and scores on the equal opportunities item and patriarchy item were not correlated at all ( $r=$ $.075 ; \mathrm{p}<.220)$.

Table 2 shows the descriptive statistics and comparison by gender for the variables measuring selfesteem, mental positivity, and attitudes to gender. 
Table 2

Descriptive Statistics and Comparison by Gender.

\begin{tabular}{lccc}
\hline \multicolumn{1}{c}{ Variable } & Men & Women & $t$ \\
\hline Self-esteem & $21.75(7.72)$ & $25.89(6.09)$ & $-4.27^{\mathrm{a}_{* * * *}}$ \\
PMI & $3.28(0.72)$ & $3.58(0.64)$ & $-2.86^{* * *}$ \\
'I am a feminist' & $2.04(1.56)$ & $3.30(1.93)$ & $-4.52^{\mathrm{a}_{* * * *}}$ \\
$\begin{array}{l}\text { Support for equal opportunities } \\
\begin{array}{l}\text { Belief partiarchy holds women } \\
\text { back }\end{array}\end{array}$ & $5.67(0.99)$ & $5.75(0.79)$ & -0.54 \\
\hline
\end{tabular}

NB: Values are shown as mean (SD), compared using independent $t$-tests.

${ }^{*} p<.05 ;{ }^{* *} p<.01 ;{ }^{* * *} p<.001$ (two-tailed)

Notes: Responses to questions about the three feminism questions were on a 6-point Likert scale from 6 (very much agree) to 1 (very much disagree)

${ }^{a}$ Equal-variances-not assumed correction used

\section{Attitudes to different types of masculinity}

Table 3 shows the participants' opinions about three concepts of masculinity.

Table 3

Percentage Participants Who Agreed with Statements Regarding Masculinity.

\begin{tabular}{|c|c|c|c|c|c|c|}
\hline \multirow[b]{2}{*}{ Agree (very much, moderately, or slightly) that: } & \multicolumn{2}{|c|}{ Traditional } & \multicolumn{2}{|c|}{ Toxic } & \multicolumn{2}{|c|}{ Positive } \\
\hline & $\mathrm{M}$ & $\mathrm{F}$ & M & $\mathrm{F}$ & $\mathrm{M}$ & $\mathrm{F}$ \\
\hline $\begin{array}{l}\text { The idea of '... masculinity' helps me to behave in a good } \\
\text { way. }\end{array}$ & 73.0 & - & 10.1 & - & 68.5 & - \\
\hline $\begin{array}{l}\text { The idea of '... masculinity' helps men in general to behave } \\
\text { in a good way. }\end{array}$ & 76.3 & 76.9 & 7.5 & 9.6 & 74.9 & 86.8 \\
\hline $\begin{array}{l}\text { The idea of '... masculinity' might make my behaviour } \\
\text { worse. }\end{array}$ & 19.9 & 30.8 & 42.7 & 65.4 & 12.3 & 37.7 \\
\hline The idea of '... masculinity' is insulting. & 24.6 & 19.2 & 87.9 & 84.6 & 33.5 & 30.2 \\
\hline $\begin{array}{l}\text { The idea of '... masculinity' changes the way we see all } \\
\text { men. }\end{array}$ & 69.2 & 61.5 & 91.5 & 86.5 & 66.5 & 60.4 \\
\hline $\begin{array}{l}\text { The idea of '... masculinity' many have a harmful impact } \\
\text { on boys if they hear or read about the term. }\end{array}$ & 28.4 & 25.0 & 88.4 & 82.7 & 27.1 & 26.4 \\
\hline The idea of '... masculinity' is helpful. & 69.7 & 71.2 & 10.1 & 21.2 & 70.0 & 69.8 \\
\hline
\end{tabular}

$n=203$ men; $n=52$ women

Table 3 shows that most of the men ( $70 \%)$ agreed that the concepts of traditional and positive masculinity would help themselves and other men behave well. In contrast, only around $10 \%$ agreed that toxic masculinity would help them. Around $43 \%$ of men thought the concept of toxic masculinity might make their behaviour worse, which is more than traditional $(20 \%)$ or positive $(12 \%)$ masculinity. Around $88 \%$ of men thought the term 'toxic masculinity' is insulting, much more than thought 
traditional $(25 \%)$ or positive (34\%) masculinity insulting. The strongest agreement was regarding how much the terms changed the way we see men in general: $92 \%$ thought the idea of 'toxic masculinity' changes the way we see all men, compared to $69 \%$ for traditional and $67 \%$ for positive masculinity. Most men (88\%) agreed that the term 'toxic masculinity' may have a harmful impact on boys who hear or read it, compared to $29 \%$ for traditional and $27 \%$ for positive masculinity. $70 \%$ of men thought the idea of traditional and positive masculinity is helpful, compared to only $10 \%$ who thought toxic masculinity was a helpful idea.

Table 3 shows that women scored similarly to men in their answers in this section, though they thought 'toxic masculinity' more helpful than men did (21\% vs $10 \%)$. Women also appeared to be ambivalent about positive masculinity; they were both more concerned that 'positive masculinity' might make men's behaviour worse ( $38 \%$ women agreed vs $13 \%$ men), and that it might help men behave in a good way ( $87 \%$ women agreed vs $75 \%$ men).

Some, but not all, feminist views were correlated with how insulting the term 'toxic masculinity' was seen: the higher the score on the 'feminist' $(r=-.45 ; p<.001)$ and 'patriarchy' $(r=-.52 ; p<.001)$ items, the less insulting men and women thought the term toxic masculinity. However, there was no correlation between agreeing with the 'equal opportunities' statement and opinions about toxic masculinity, for men or women.

\section{Predictors of self-esteem}

Regression analysis was conducted on the male sample only because the female sample was below the minimum suggested by sample size analysis. The model (Table 4) performed significantly better than chance $[F(8,187)=6.99, p<.001]$ and borderline moderately predicted the amount of variation in selfesteem (Adjusted R Square $=19.7 \%$ ).

Table 4 shows that men had higher self-esteem if they were older $(\beta=.305)$, had more education $(\beta=$ $.217)$, and expressed an agreeable attitude to traditional masculinity $(\beta=.159)$.

Table 4

Predictors of Self-Esteem in the Male Sample Only

\begin{tabular}{lccc}
\hline \multicolumn{1}{c}{ Variable } & $B$ & SE B & $B$ \\
\hline Age & .028 & .006 & $.305^{* * * *}$ \\
Education status & .150 & .047 & $.217^{* *}$ \\
Attitude to traditional masculinity & .165 & .082 & $.159^{*}$ \\
Attitude to toxic masculinity & .095 & .099 & .077 \\
Attitude to positive masculinity & -.002 & .074 & -.002 \\
Identification as a feminist & .039 & .059 & .051 \\
Support for equal opportunities & .046 & .079 & .038 \\
Belief patriarchy holds women back & -.033 & .070 & -.040 \\
\hline
\end{tabular}

${ }^{*} p<.05 ;{ }^{* *} p<.01 ;{ }^{* * *} p<.001$ (two-tailed) 


\section{Predictors of mental positivity (PMI)}

Regression analysis was conducted on the male sample only. The model (Table 4) performed significantly better than chance $[F(8,187)=4.092, p<.001]$ but only weakly predicted the amount of variation in self-esteem (Adjusted $\mathrm{R}$ Square $=11.3 \%$ ). The weakness of the model reflects the fact that most of the predictors did not contribute significantly to the model.

Table 5 shows that men had a more positive mindset if they were older $(\beta=.196)$, expressed an agreeable attitude to traditional masculinity $(\beta=.178)$, and had more education $(\beta=.151)$.

Table 5

Predictors of PMI in the Male Sample Only

\begin{tabular}{lccc}
\hline \multicolumn{1}{c}{ Variable } & $B$ & SE B & $B$ \\
\hline Age & .011 & .004 & $.196^{* *}$ \\
Education status & .064 & .030 & $.151^{*}$ \\
Attitude to traditional masculinity & .114 & .053 & $.178^{*}$ \\
Attitude to toxic masculinity & .043 & .064 & .057 \\
Attitude to positive masculinity & .026 & .048 & .041 \\
Identification as a feminist & .049 & .038 & .106 \\
Support for equal opportunities & .059 & .051 & .080 \\
Belief patriarchy holds women back & -.046 & .045 & -.093 \\
\hline
\end{tabular}

${ }^{*} p<.05 ;{ }^{* *} p<.01$ (two-tailed)

\section{Attributing work or relationship problems to gender}

Participants were asked: If you were feeling down because your job was making you stressed and you were told that your problems were caused by your masculinity, how would you feel?' The response options were the six PMI items. All items scored in the same direction, but the largest responses were for the first item (happiness), and for the sake of brevity only findings for the first item are presented here.

In response to the question, $86.7 \%$ of men said they would feel unhappy or very unhappy. A similar question about 'relationship problems' found $87.5 \%$ of men would feel unhappy or very unhappy. Similar questions to women about their femininity being blamed found similar levels of unhappiness or very unhappiness for their job (94.1\%) or relationship (84.6\%) problems.

\section{Free text responses}

Participants were asked: What do you think is the main cause of men's extremely bad behaviour?' $84.6 \%$ of participants responded, and content analysis of the free text found nine categories: $23.9 \%$ blamed various aspects of society; a further $19.5 \%$ blamed fatherlessness/ absence of role models; $11.5 \%$ blamed upbringing/ childhood issues; $10.6 \%$ blamed a combination of nature \& nurture; $8.4 \%$ blamed the individual; 8.0\% blamed mental illness (including drug and alcohol); $4.9 \%$ blamed trauma; $4.0 \%$ blamed feminism/ intersectionality; $1.8 \%$ blamed patriarchy. Also, $7.5 \%$ of participants said they didn't like the question, or some aspect of the survey. It was notable that in the various responses, social factors were blamed much more for bad behaviour than the individuals. 


\section{DISCUSSION}

The purpose of this survey was to explore opinions on contemporary narratives about masculinity. It was found that most participants had concerns about the term toxic masculinity and blaming gender for work or relationship problems. It was also found that higher self-esteem in men was associated with agreement with traditional masculinity.

\section{Opinions about different types of masculinity}

Although the term 'toxic masculinity' might have been intended originally to be applied only to a minority of men, there is reason to be concerned that such terminology inevitably taints all men, in the same way that prefixing 'toxic' to any demographic might taint the people of that demographic (Barry, 2017). Such concerns gain validation in the present study, because $92 \%$ of male participants (and $87 \%$ of female participants) agreed that the idea of 'toxic masculinity' changes the way we see all men.

The present study is the first to quantify concerns about the impact of the narrative around 'toxic masculinity' for boys. Most men (88\%) agreed that 'toxic masculinity' may have a harmful impact on boys who hear or read the term, compared to $29 \%$ with concerns about traditional masculinity and $27 \%$ for positive masculinity. Given that previous research has found that boys are more quickly associated with negative attributes than are girls (Heyman, 2001), further research - followed by public discussion - is needed about the impact on boys of negative narratives about masculinity. For example, schools should be aware of the implications of workshops which could inadvertently make boys feel negatively about themselves by virtue of their gender (Innes-Smith, 2020).

Around $23 \%$ of male and $54 \%$ of female participants agreed (either very much, moderately or slightly) that they were feminists, which is a similar rate for men in a recent poll of the UK general population (18\%), though noticeably higher than found for women in the poll (34\%) (YouGov, n.d.). This means the findings of the present study are more generalisable to men than women in the UK population. In the present study, compared to those identifying as feminists, fewer agreed they held anti-patriarchy views (around $16 \%$ of men and $43 \%$ of women). The finding that anti-patriarchy views were correlated with more approval of the 'toxic masculinity' narrative, whereas equality of opportunity views were not, suggests the need for a more nuanced discussion about the impact of feminism on men than is often seen. Specifically, discussions should distinguish between 'equal opportunities' feminism, which appears to be benign towards masculinity, and 'anti-patriarchy' feminism which is significantly correlated with negative views of masculinity. It was interesting that scores on the equal opportunities item and patriarchy item were not correlated at all, suggesting that views on one are not related to views on the other.

\section{Traditional masculinity and self-esteem}

Previous research has found that low self-esteem is correlated with suicidal ideation (De Man \& Gutiérrez, 2002), and that feeling good about masculinity is good for men's self-esteem (Burkley et al., 2015). The present study found an association between having a favourable view of traditional masculinity and self-esteem and is the first study to find a correlation between traditional masculinity and mental positivity (PMI). Self-esteem and PMI were associated with being older and being more highly educated, and even after taking these into account, there was a modest but statistically significant association between self-esteem and having a favourable view of traditional masculinity. Age is important here too: the demographic most at risk of suicide in many Western countries is middleaged men, and the present study - where the mean age of men was 45 years old - suggests that valuing traditional masculinity might be protective of self-esteem and mental positivity. Because the PMI is strongly inversely correlated with suicidality (Seager et al., 2014), it is possible that traditional masculinity could be a barrier against suicidality. These correlations need to be replicated with further research, but they beg the question of the wisdom of approaches to therapy which undermine 
traditional masculinity. This negative approach to masculinity has been suggested in the US (APA Guidelines for Psychological Practice with Boys and Men, 2018) and the UK (Power Threat Meaning Framework, PTMF) (Johnstone \& Boyle, 2018). Although it is possible that men who have specific issues with masculinity or patriarchy might benefit from such interventions, such interventions might risk damaging self-esteem and mental positivity of other men without such issues. Research into the safety and efficacy of anti-masculinity / anti-patriarchy approaches is needed.

\section{Impact of gender on job and relationship problems}

Masculinity/patriarchy have been suggested to hold back women's careers (Rao, 2016), or cause problems in relationships (Johnstone \& Boyle, 2018). In the present study, when asked how happy they would feel if problems with their job were blamed on their gender, $86.7 \%$ of men said they would feel unhappy or very unhappy. A similar question about relationship problems found $87.5 \%$ of men would feel unhappy or very unhappy. The same questions to women about their femininity being blamed found similar levels of being unhappy or very unhappy regarding their job (94.1\%) or relationship (84.6\%) problems.

These findings suggest that people don't like it when their gender is blamed for their problems. Although these questions were not asked specifically in relation to a therapist blaming their gender for their problems, it would be interesting to see what future research would find if the question were phrased in this way. Blaming gender might put people off seeking psychological help; it might alienate existing clients, and even potentially make their problems worse (Ferguson, 2018).

Principle A of the APA Code of Ethics is that 'Psychologists strive to benefit those with whom they work and take care to do no harm' (American Psychological Association, 2002). Regarding gender identity, the British Psychological Society says: 'Conversion therapy is the term for therapy that assumes certain sexual orientations or gender identities are inferior to others and seeks to change or suppress them. It is unethical, potentially harmful and is not based on any reputable evidence' (BPS, 2019). It makes sense that these values should be applied to traditional masculinity. One barrier to this, however, is that the APA view masculinity as simply as a social construct without any biological basis (APA Guidelines for Psychological Practice with Boys and Men, 2018). Following from this premise, if masculinity is simply a learned behaviour, then perhaps it can simply be unlearned. However, this social-learning reductionist view is a false premise that fails to account for the wealth of evidence that many of the physical and psychological phenomena that we associate with masculinity may have a biological basis (Barry \& Owens, 2019) and appear across cultures (Ellis, 2011). Even if there were no biological basis to masculinity and it was simply a socially learned set of beliefs, it is still highly questionable that therapists should treat traditional masculinity as pathology, any more than they would treat any other traditional beliefs as pathology. The fact that traditional masculinity is likely to be to some degree innate and prevalent should cast doubt over attempts to pathologise it, especially as part of a mental health intervention.

Although the term 'toxic masculinity' is supposedly intended to describe only the negative behaviours that men engage in, it is difficult to see how the contemporary mainstream discourse does not create a negative aura around men in general. This implicit generalisation of toxicity not only deflects attention from the fact that most of the crime is committed by a minority of criminals (Farrington, 1995), but equally importantly that the outliers of many distributions are disproportionately male (the 'variability hypothesis'; Ellis, 2010). Thus, although men might form the most extreme cases (positive and negative), the extreme cases - the statistical outliers - are not typical of most men.

\section{Strengths of the present study}

This study is to first to attempt to address important questions regarding narratives around masculinity, and how they might impact men and boys. The findings of this study might inspire further work in this topic, for example, future studies might focus on specific populations identified in this study, such as schoolchildren who have been exposed to workshops, clients of therapists who have been trained to see 
masculinity as a problem, as well as the wider general population who may well be frustrated that the prevailing narrative generally goes unchallenged.

The starting point for recruitment was the Male Psychology Network social media, which might tend to attract participants who are positively disposed to masculinity. However not all of the views expressed in the study were positive to masculinity, indicating that some diversity of views were accessed within the sample. The study sample included slightly more people identifying as feminists than found in the general population (YouGov, 2018), and overall might be seen as reasonably generalisable.

\section{Weaknesses of the present study}

Being a pilot investigation, this study inevitably has some weaknesses. For example, the number of women was relatively small compared to the number of men. On the other hand, because men are the main focus of the present study, this is probably acceptable. Also, some of the scales (the three measures of masculinity, and the three feminism items) used were bespoke for this study and not validated. Further research should refine these instruments or use validated measures.

Although the invitation to the survey was open to men and women (the invitation did not specify the gender of participants wanted), the survey attracted mostly men, at a ratio of 4:1. This gender ratio in responding is unusual, and it appears that the women who answered had significantly higher selfesteem scores 25.89 (6.09) than the male participants 21.75 (7.72). Men and women had scores within the normal range (15-25), though men were in the middle of the range and women were at the borderline for 'high self-esteem'. This difference might mean that comparisons between men and women might not generalise very well, though this does not impact the findings based on the men-only analyses in this study.

There was good statistical power for analysis of men's data in the present study, but lower statistical power for tests of women's data. For example, for multiple linear regression (Table 4) the recommended sample size for eight predictors is 114 participants, and the lower number of female participants in this study $(n=52)$ means that any non-significant findings might have been due to low statistical power (a type 2 error), and for this reason multiple linear regressions were not conducted for the female sample. However, for the purposes of this study, men's views were more sought after, thus the lower statistical power of analyses including women does not undermine the findings from the male sample. It would have been interesting to see the opinions of transgender people regarding masculinity, but only two transgender people participated, which is too few to conduct meaningful statistical analysis.

\section{CONCLUSION}

Gender differences are part of the human condition, and such differences will inevitably create different pressures and issues for men and women over and above their common interests and common humanity. Whilst modern women, despite social and political change, remain under pressure to conform to evolved female archetypes such as beauty and mothering, men remain under equal pressure to conform to equivalent archetypes of strength, risk-taking and protection (Seager et al, 2014). The male archetype itself may be said therefore to breed less societal empathy for the gender that is expected to take risks and provide physical protection. However, rather than challenging this view of men by moving to a more equal position of greater empathy, contemporary socially constructed Western narratives of gender, reflected both in social policy and the media, are in danger of amplifying these archetypal differences even further. Even within the realms of mental health, psychology and social science, current frameworks and concepts relating to gender, being founded in judgemental, rather than compassionate, notions of male power, patriarchy and even toxic masculinity, may be leading to a "double whammy" of lower self-esteem in men coupled with decreased compassion for them (Seager \& Barry, 2019). This is an important public health issue for our society, and we hope that the present study is the first of many to investigate the impact of social attitudes on men and boys. 


\section{REFERENCES}

Acharya, S. \& Relojo, D. (2017). Examining the role of cognitive distortion and parental bonding in depressive symptoms among male adolescents: A randomised crossover trial. Journal of Innovation in Psychology, Education and Didactics, 21(1), 7-20.

https://doi.org/10.5281/zenodo.1289149

American Psychological Association (2002). Ethical principles of psychologists and code of conduct. American Psychologist, 57.12), 1060-1073. https://doi.org/10.1037/0003-066x.57.12.1060

Arfken, M. (2017). Marxism as a foundation for critical social psychology. In The Palgrave handbook of critical social psychology (pp. 37-58). Palgrave Macmillan. https://doi.org/10.1057/978-1-13751018-1 3

American Psychological Association (2018). APA guidelines for psychological practice with boys and men. PsycEXTRA Dataset.https://doi.org/10.1037/e505472019-001

Barry, J. A., Folkard, A., \& Ayliffe, W. (2014). Validation of a brief questionnaire measuring positive mindset in patients with uveitis. Psychology, Community \& Health, 3(1), 1-10. https://doi.org/10.5964/pch.v3i1.76

Barry, J.A. (2017). Loosening the male stiff upper lip. The World Today. Retrieved from https://www.chathamhouse.org/publications/twt/loosening-male-stiff-upper-lip

Blascovich, J., \& Tomaka, J. (1991). Measures of self-esteem. In Measures of personality and social psychological attitudes (pp. 115-160). https://doi.org/10.1016/b978-0-12-590241-0.50008-3

British Psychological Society. (2019). A psychological manifesto. Retrieved from https://www.bps.org.uk/news-and-policy/psychological-manifesto

Burkley, M., Wong, Y. J., \& Bell, A. C. (2016). The Masculinity Contingency Scale (MCS): Scale development and psychometric properties. Psychology of Men \& Masculinity, $17(2), 113-125$. https://doi.org/10.1037/a0039211

Cicone, M. V., \& Ruble, D. N. (1978). Beliefs about males. Journal of Social Issues, 34 (1), 5-16. https://doi.org/10.1111/j.1540-4560.1978.tb02537.x

Cohen, J. (2013). Statistical power for the behavioural sciences (2 $2^{\text {nd }}$ ed.). Routledge. .https://doi.org/10.4324/9780203771587

De Man, A. F., \& Gutiérrez, B. I. B. (2002). The relationship between level of self-esteem and suicidal ideation with stability of self-esteem as moderator. Canadian Journal of Behavioural Science / Revue Canadienne Des Sciences Du Comportement, 34(4), 235-238. https://doi.org/10.1037/ho087176

Ellis, H. (2010). Man and woman: A study of human secondary sexual characters. American Anthropologist, 73).327. https://doi.org/10.1525/aa.1894.7.3.02a00080 
Ellis, L. (2011). Identifying and explaining apparent universal sex differences in cognition and behaviour. Personality and Individual Differences, 51(5), 552-561.

https://doi.org/10.1016/j.paid.2011.04.004

Farrington, D. P. (1995). The twelfth Jack Tizard memorial lecture. Journal of Child Psychology and Psychiatry, 36(6), 929-964. https://doi.org/10.1111/j.1469-7610.1995.tb01342.x

Ferguson, C. (2018). Peer-review of draft guidelines for psychological practice with boys and men. https://www.scribd.com/document/385347642/Review-of-Practice-Guidelines-for-Men-andBoys

Graneheim, U. H., \& Lundman, B. (2004). Qualitative content analysis in nursing research: Concepts, procedures and measures to achieve trustworthiness. Nurse Education Today, 24(2), 105-112. https://doi.org/10.1016/j.nedt.2003.10.001

Harlow, L.L. (2002). Using multivariate statistics. Structural Equation Modeling: A Multidisciplinary Journal, 9(4), 621-636. https://doi.org/10.1207/s15328007sem0904 9

Heyman, G.D. (2001). Children's interpretation of ambiguous behaviour: Evidence for a 'boys are bad' bias. Social Development, 10(2), 230-247. https://doi.org/10.1111/1467-9507.00161

Hinkle, D. E., Wiersma, W., \& Jurs, S. G. (2003). Applied statistics for the behavioural sciences (Vol. 663). Houghton Mifflin College Division.

Innes-Smith, J. (2020). The seven ages of man: How to live a meaningful life. Constable.

Johnstone, L. \& Boyle, M. (2018). The power threat meaning framework: An alternative nondiagnostic conceptual system. Journal of Humanistic Psychology.

https://doi.org/10.1177/0022167818793289

Kupers, T. A. (2005). Toxic masculinity as a barrier to mental health treatment in prison. Journal of Clinical Psychology, 6r(6), 713-724. https://doi.org/10.1002/jclp.20105

Mahalik, J. R., Locke, B. D., Ludlow, L. H., Diemer, M. A., Scott, R. P., Gottfried, M., \& Freitas, G. (2003). Development of the conformity to masculine norms inventory. Psychology of Men \& Masculinity, 4(1), 3-25. https://doi.org/10.1037/1524-9220.4.1.3

Nathanson, P., \& Young, K. K. (2009). Coming of age as a villain: What every boy needs to know in a misandric world. Boyhood Studies, 3(2), 155-177.

Nicolson, P. (2010). Domestic violence and psychology: A critical perspective( $1^{\text {st }}$ ed.). Routledge. https://doi.org/10.4324/9780203093092

Paykel, E. S., Myers, J. K., Lindenthal, J. J., \& Tanner, J. (1974). Suicidal feelings in the general population: A prevalence study. The British Journal of Psychiatry, 124(582), 460-469. https://doi.org/10.1192/bjp.124.5.460

Pek, J., Wong, O., \& Wong, A. C. M. (2018). How to address non-normality: A taxonomy of approaches, reviewed, and illustrated. Frontiers in Psychology, 9. https://doi.org/10.3389/fpsyg.2018.02104 
Phillips, B. N., Reyes, A., Kriofske Mainella, A. M., Kesselmayer, R. F., \& Jacobson, J. D. (2018). A needs driven model of workplace social effectiveness in adults with disabilities. Rehabilitation Counseling Bulletin, 62(1), 30-42. https://doi.org/10.1177/0034355217747690

Rao, A. (2016). Challenging patriarchy to build workplace gender equality. Retrieved from https://www.raco.cat/index.php/IUSLabor/article/download/312028/402126

Rosenberg, M. (1965). Society and the adolescent self-image. Princeton University Press

Seager M., Barry J.A. (2019) Positive masculinity: Including masculinity as a valued aspect of humanity. In: Barry J., Kingerlee R., Seager M., Sullivan L. (eds.). The Palgrave handbook of male psychology and mental health (pp. 105-122). Palgrave Macmillan. https://doi.org/10.1007/978-3030-04384-1 6

Seager, M., Sullivan, L., \& Barry, J. (2014). Gender-related schemas and suicidality: Validation of the male and female traditional gender scripts questionnaires. New Male Studies, 3(3), 34-54.

Sharma, N., \& Sharma, K. (2015). Self-fulfilling prophecy: A literature review. International Journal of Interdisciplinary and Multidisciplinary Studies (IJIMS), 2(3), 41-42.

Spence, J. T., Helmreich, R., \& Stapp, J. (1975). Ratings of self and peers on sex role attributes and their relation to self-esteem and conceptions of masculinity and femininity. Journal of Personality and Social Psychology, 32(1), 29-39. https://doi.org/10.1037/h0076857

Stacey, J. \& Connell, R.W. (1988). Gender and power: Society, the person and sexual politics. Contemporary Sociology, 175), 595-596. https://doi.org/10.2307/2073932

Tabachnick, B. G., and Fidell, L. S. (2001). Using multivariate statistics (4th ed. ). Allyn and Bacon.

World Medical Association. (2013). WMA - The World Medical Association-WMA_declaration of Helsinki - Ethical principles for medical research involving human subjects. Retrieved from https://www.wma.net/policies-post/wma-declaration-of-helsinki-ethical-principles-formedical-research-involving-human-subjects 